\title{
OLD WINE IN NEW BOTTLES - AN ALTERNATIVE DIDACTIC APPROACH TO TOOLS USED IN FASHION DESIGN
}

\author{
Anne Louise BANG ${ }^{1}$ and Malene PILGAARD HARSAAE ${ }^{2}$ \\ ${ }^{1}$ Centre for Creative Professions \& Industries, VIA University College, Denmark \\ ${ }^{2}$ VIA Design + Business, VIA University College, Denmark
}

\begin{abstract}
Design disciplines in general are challenged to foster alternative solutions towards a green transition of the industry. This naturally effects the design educations where the majority of curriculums include various learning objectives regarding sustainability, circular economy, re-cycling, etc. However, in this paper, we argue that many of the traditional tools and skills already inherent in the curriculums have the potential to promote a green transition provided they are introduced differently. Using well-known tools and skills in alternative ways is however challenging as the way in which their use is articulated and presented by lecturers determine the way in which the student implements and makes use of the tools. This article explores whether and how an alternative use of well-known tools in a fashion design context can beneficially contribute to increased product awareness among students and thereby support a sustainable development of the fashion industry. We suggest using the professional tools "line-up" and "collection plan" as anti-poles for the creation of a space for critical reflection. The anti-poles respectively address fashion as dreams and fashion as products. Fashion is a very visible part of consumption. As a concept that involves planned obsolescence, it is a major sinner in polluting the environment. Consequently, fashion design provides a relevant case to explore whether well-known tools and skills submitted through an alternative didactic approach, predominantly through articulation, can contribute to foster design students' ability to contribute to sustainable development in design and engineering education in general.
\end{abstract}

Keywords: Critical reflection, well-known tools, green transition, didactic approach, fashion design

\section{INTRODUCTION}

Institutions, organizations, and researchers within the realm of fashion predominantly agree that the fashion industry faces a paradigm shift towards a green transition. Time has come to leave the fast fashion system established in the 1990s with its one-eyed focus on sending endless numbers of cheap garments to the market in a continuous stream that promotes product detachment and frequent replacement resulting in piles of products that are under-used before they are sent to landfills. The good news is that several companies have embarked on the sustainable and circular journey. Fashion design curriculums in general have an intensified focus on sustainability. Policy makers worldwide set goals for the industries to reduce or stop harmful influence on the environment. Consumers are becoming increasingly aware of acting more sustainably when it comes to garment consumption. However, there is still a long way to the full green transition of the industry. There are numerous obstacles to a green transition; the fashion industry is paradoxically rather conservative in terms of new approaches and alternative business models. It is predominantly trend-led and profit-oriented with an overall linear value chain. On top of that, the take-back and recycle systems are still in an early development phase.

Not only is the traditional mindset in fashion design exposed to necessary disruption. Product design and engineering disciplines in general are currently faced with a demand to think differently in order to contribute to a green transition of society. Thinking differently requires us to reconsider what we usually do and to change our mindsets towards alternative goals approaching them in other ways than usual. It can be beneficial to look at the realm of fashion design as a case study Partly because the concept of fashion with the notion of impermanence, rapidity, and an interminable succession of accumulative obsolescence in the products offered to consumers permeates the consumption of products in general. 
Lipovetsky [1] uses the concept of fashion and its ostensibly persistent pursuit of novelty to present his construction of a transformation from post-modern to 'hyper-modern' times. A transformation he interprets as " $a$ 'society of fashion' restructured [...] by the technologies of ephemerality, novelty and permanent seduction" and continues to describe as "a world of seduction and ceaseless movement, whose model is none other than the system of fashion" [1:36]. Additionally, the practice of fashion design provides a particularly interesting case as it continuously distinguishes and navigates between the intangible concept of fashion and the tangible clothing products [2].

As fashion design educators and researchers, we find it highly important to influence the industry by the way we develop the curriculum and teach the fashion design students. It may be that the chances of influencing the processes in design and product development are few. Nevertheless, we provide the future designers with skills and competencies that allow them to contribute to the transformation of the system whenever it is possible. We aim to give the future designers an expertise that can be utilized to its full potential regardless of whether they are working in companies that are preparing a systemic shift or companies that are much longer on this journey. Thus, this paper seeks to initiate a discussion about ways in which well-known fashion design tools such as "line-up" and "collection plan" can be used didactically in our efforts to prepare the students to contribute to sustainable development of the industry and thereby a green transition of society.

\section{PRODUCT FOCUS IN AN EXPERIENCED REALITY}

In "The Earth Logic Action Research Plan" Fletcher and Tham's objective is to radically change our mindsets towards a green transition by placing the Earth before profit, demanding a systemic change before it is too late [3]. They build their arguments on an awareness towards resistance to paradigmatic change, suggesting that we think of fashion not only as garments but as "new relationships between people, other species, artefacts and technologies [3: 14]. In relation to this, we emphasize that in a fashion context it is rarely the case that fashion is experienced as pure garments. Fashion is concepts, dreams, style, trends, etc. Therefore, we suggest establishing what we call a product focus in an experienced reality. Product focus is about being preoccupied with the individual product in the lived and experienced reality and critically evaluate the justification of every single product that is designed and developed.

Using a thorough consideration and reflection on the value of each product in relation to the intended use and/or user as our starting point, we aim to provide the future designers with a space for critical reflection. With this article, we want to explore and discuss the possibility of taking the well-known and often used tools and techniques "line-up" and "collection plan" from the fashion design education and industry and turn them into tools for contemplation and systems change. Drawing on Lehrdahl's framework [4] illustrating the movement from the abstract to the concrete, from intention to product focus, we suggest that a dialogue and conversation about the conceptual idea of a product (the line-up) versus the concrete and real product (the collection plan) will foster students' critical reflection and thus contribute to a systemic change of design and product development in the fashion and textile industry. Thus, the point of departure is to address and pinpoint the somehow abstract intention, creating a space for critical reflection towards the concrete garment or product with the aim of supporting sustainable and responsible consumption and production as expressed in the United Nations Sustainable Development Goal number twelve [5].

In his seminal work on experience and education, Dewey discusses traditional versus progressive education arguing that critical examination of underlying principles must form the starting point of ways in which we develop a new mindset for our teaching [6]. His work is still highly relevant since we experience a time where we are forced to change what can be understood as a traditional way of educating fashion designers into a new and still unknown territory of a greener industry of which we can only begin to grasp the contours. In our considerations, we want to acknowledge that fashion designers, as other designers, are practitioners. Many practitioners in the field of design probably perceive themselves as reflective practitioners. The process of knowledge production, which takes place in practice, is described by Schön as "a conversation with the material of a situation" where the practitioner reflects in and on practice [7]. The challenges are that the material of a situation in relation to sustainable solutions is about creating a space for dialogue between the untrodden and unknown territory and the materials. The designer is the agent reflecting in and on practice and in a context where strategies and other practitioners also play a role. This paper is speculative as we debate whether we can use well-known tools - in the specific case line-up and collection plan - to create a space for dialogue 
that promotes the conversation with the material of a situation and thus contributes to creating the required new mindset through increased critical reflection by educators as well as students.

Karell and Niinimäki argue that fashion designers traditionally are seen as "translators of creative ideas into profitable products" but also acknowledge that "design can influence numerous aspects in the production and consumption of products" [8: 2]. In a Finnish study with 31 respondents, including designers from sustainable-minded clothing companies and among them a number of micro companies, the most significant barrier mentioned for contributing to 'sustainable strategic (design) decisions' is lack of knowledge [8]. While we agree that knowledge is important, we wish to point to the possibilities embedded in connecting a shift in mind-set to the traditional tools and techniques used by fashion designers. That is, the knowledge that stems from professional skills and tools. In the following sections, we introduce the line-up and the collection plan to exemplify such tools that we see bear the potential to be applied in a different way didactically.

\subsection{Line-up}

In fashion design education, a line-up is a communication tool consisting of an assembly of several fashion drawings illustrating the fashion concept in a visual and storytelling way. The design brief for most fashion projects at VIA Design \& Business includes the line-up as part of the student's solution and presentation of the project and generally outlines a minimum number of outfits that the project and thus the line-up (solution) should consist of. As a communication tool, the line-up provides a quick-tograsp impression of the fashion collection, the design universe, silhouettes, and aesthetics. At the same time, however, the line-up supports an implicit maintenance of a traditional view of illustrating a collection, and there is a risk that not all the products in the final collection will be considered in-depth. This may cause the designer to fail to evaluate the value and justification of the individual product in the real world and focus on the value of the overall impression instead. Thus, inadvertently creating products that do not capture a user. The maintenance of this traditional view of a collection predominantly derives from the lecturers' introduction of the methods, which thus influences and governs the students' solutions. Students are less likely to be innovative in their collection development if the lecturers maintain and communicate their traditional perception of a collection.
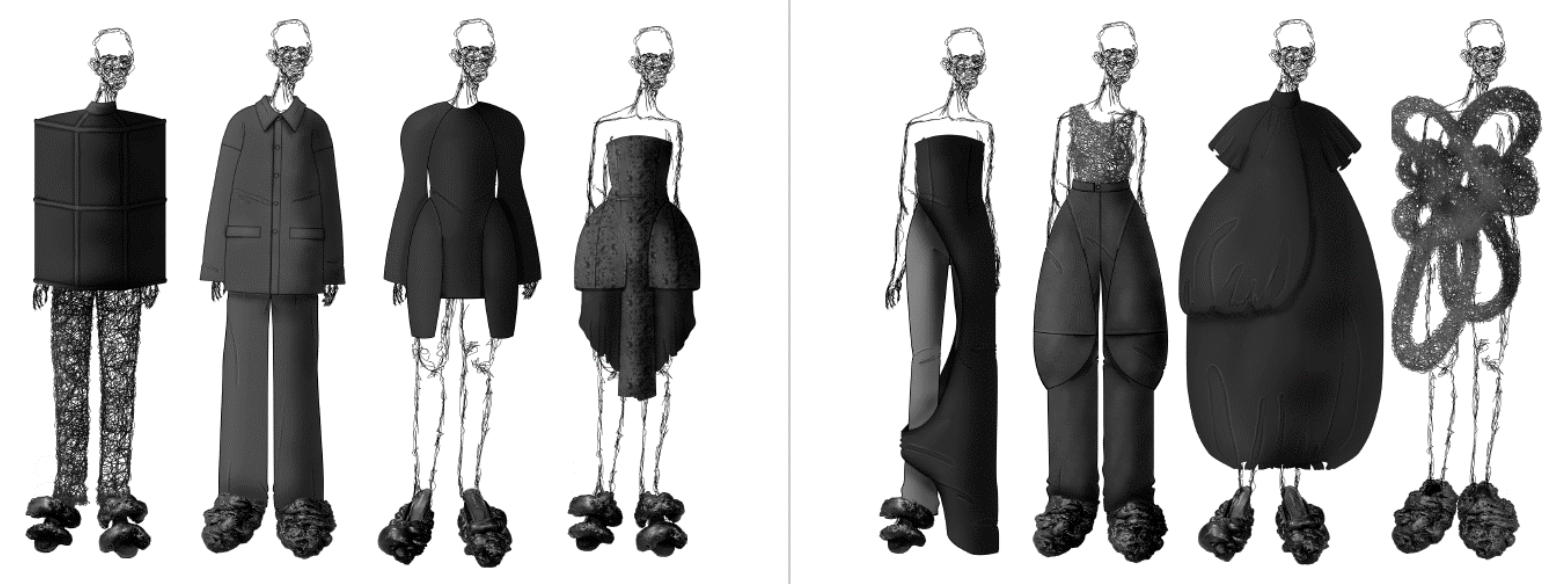

Figure 1. A line-up by student Louise Kristiansen, VIA Design \& Business, 2020

\subsection{Collection plan}

A collection plan - or range plan - is a more schematic tool, which is applicable both as a business tool, as a strategic tool, and as a structuring tool to support the design universe and the aesthetic concept. The collection plan illustrates and communicates each product in detail in terms of form, shape, materials, colours, etc., making it possible to address each product individually and evaluate the characteristics and environmental implications of each product. At the same time, it can be used to evaluate the value for the intended user, not only as part of a concept, but the relevance and applicability of each product in itself. The collection plan can support a critical reflection of the justification and necessity of a single product. Is it just there to 'glue the collection together', or is it actually relevant and value-creating in itself? 


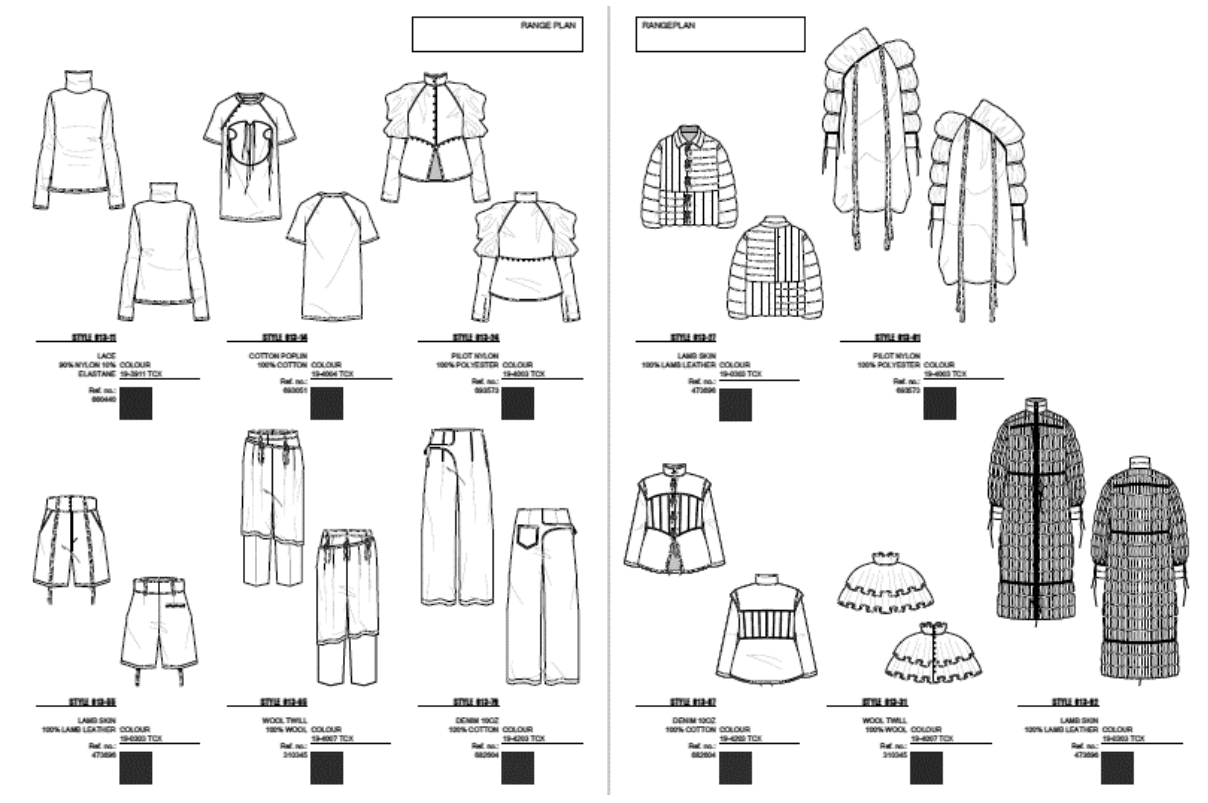

Figure 2. A collection plan by student Louise Kristiansen, VIA Design \& Business, 2020

Articulating the space between line-up and collection plan as a space for dialogue between the dream world of the fashion industry and the real world of the users' interaction with the actual clothing products is an attempt to create a space for critical reflection. Addressing each products' life cycle and ensuring that each product both enters and leaves the world in a responsible and sustainable way will inevitably contribute to sustainable development of garment design. It is additionally recommendable to understand and explore use niches as a path to create product attachment, often emphasized as a contribution to a more responsible and sustainable fashion product consumption.

\section{EXEMPLIFYING CRITICAL REFLECTION}

In this section, we will exemplify the space for critical reflection between two companies' use of narratives and the actual product range. We have selected two companies that both work with alternative approaches to garment design compared to more traditional ways of building a fashion collection. Their mind-set and approach are not unknown but also not widespread in the fashion industry. Both companies are niche companies demonstrating alternatives to traditional collection building by having a limited product portfolio and thus an increased product focus. They have developed business models and strategies which are alternatives to the traditional and still dominant fast fashion approach to fashion design, and both companies are financially sustainable. The two companies actively use critical reflection in their design development. None of them specifically accentuates line-up as a used tool, instead they highlight a strong narrative and a conscious attitude as their strategy for how and why they make clothes, and then they use the collection plan as a tool for critical reflection and product evaluation. Though their business concepts, collection structures (plan) and thus design process are different, both Andersen-Andersen [9] and Week of Wonder [10] employ a product-focused approach. This derives from their strategic dispositions with sustainability as an anchoring point in their business models; both from an economic as well as from an environmental point of view. Both companies aim for the paradox of designing for a diversity of segments with a limited number of products and product groups. In this way, they counteract the dominating approach in the industry - and especially the fast fashion industry - of designing and developing numerous products that may or may not appeal to the users.

Andersen-Andersen works with longevity understood as durability - material, manufacturing, form, and styles that are in the collection several years, and they acknowledge that development takes time. They design and produce knitwear where they have created their own niche of traditional, sailor-inspired sweaters and blouses. Wolf, CSR Manager of Andersen-Andersen, describes how the long-term and set collection plan guides the development of new products. "Our products are designed for longevity. We offer the same items to the customer year after year, and the development of new styles or colours are 
a time-consuming and strategic decision" (quote from interview conducted Jan 2021). This strategy has certain implications. An example is the lack of emphasizing additional sales and a careful selection of retailers that acknowledge Andersen-Andersen's values.

Week of Wonder similarly works with longevity in the form of durability in material, manufacturing, form, and aesthetics. Styles are repeated and kept in the collection for more seasons, however, in a variety of material options. All products are made-to-order to ensure that each product is produced for an intended user, thus increasing the probability of product attachment, and avoiding sale and reduced prices. Vestergaard, CEO of Week of Wonder, clearly states how the development of the collection plan governs the methodical and strategic approach to the development of the collection. "I evaluate the applicability and achievement of needs in each product type in relation to my clientele before working with the aesthetic expression" (quote from interview conducted Jan 2021). As Vestergaard's sustainable approach partly includes a strategic decision to develop only few styles to create a collection that will hit different types of women, she emphasizes the importance of her initial work with the collection plan. We contend that an increased preoccupation with and focus on the individual product and the interaction between product and user in the experienced reality as exemplified by the two companies contributes to designing valuable and long-lasting products and thus to more responsible and sustainable consumption and production. This approach also supports a transformation from a focus on fitting into a fashion context to a focus on products designed for real use and product attachment. Thus, the two companies exemplify the critical space for reflection, which we discuss in this paper.

\section{TOWARDS A NEW DIDACTIC MINDSET}

In the previous sections, we have discussed how the space for critical reflection may emerge between the perceptions of dreams of fashion to dreams of use. In this section, we sum up our discussion and arguments for an alternative didactic approach to professional and well-known tools and methods for fashion design.

\subsection{The space for critical reflection}

The ability to create a space for critical reflection depends largely on the educator's ability to abandon and unlearn an understanding that has been trained through many years of practice and has therefore become an inherent pre-conception of the nature of a collection and the fashion system. In order to be able to foster the shift, the starting point must be that we as educators change our mindset and do away with our own well-established notions of professions and industries in general and, in this paper, specifically fashion design. We must take it upon ourselves to articulate a new teaching paradigm replacing the traditional 'way' of designing fashion. Changing the mindset touches something deep inside us. It is a balance. Using line-up and collection plan to create a space for critical reflection intends to foster the students' awareness of and curiosity towards the alternative possibilities that may arise between the abstract and the concrete. Critical reflection thus becomes an approach to evaluate the value of each individual product but also a tool for evaluation of the justification of each product category, contributing to foster ideas for concepts consisting of mono product collections aka Andersen-Andersen or limited product category collections aka Week of Wonder.

\subsection{From dreams of fashion to dreams of use}

We often get the feedback from students that it can be difficult to both fulfil the needs of the companies and contribute to strategic solutions concerning sustainable development. Didactically, we provide the students with skills that make them employable and skills that enable them to act strategically and contribute to change and development. The fashion design students are faced with the dilemma of acting as responsible contributors to a new normal where sustainability and responsibility is not related to a question of if, but rather a question of how. For some students, this attitude counteracts their dream of being a player in the fashion world and create dreams. Fashion design students develop an array of skills. Thus, we have a task and a responsibility to encourage the students to establish their 'dream of use' instead of maintaining a (maybe outdated) 'dream of fashion'. As educators, we strongly believe that we have a responsibility to promote a new paradigm and system within fashion design. To do this, we need support from the political system and the industry as well as another way of using and consuming garments. 


\section{CONCLUDING REMARKS}

The advantage of using line-up and collection plan to create the space for critical reflection is rooted in the fact that the tools are already part of the curriculum and thus well-known tools for the students and lecturers alike. Thus, introducing line-up and collection plan as dialogue tools for sustainable development does not require changes in curriculums. Students as well as educators can begin the change in mindset from a safe space, incorporating well-known tools and techniques in the processes. However, it does require a different didactic approach to the introduction and use of the tools. It is about introducing and articulating their use differently. On the basis of earlier experiences, we expect that interaction between design work and dialogue - reflection in action - will create a fruitful space for research [11]. Thus, further researching this proposed educational methodology as it takes place in the classroom will provide us with examples of initiating a critical discussion among students.

In this paper, we point to the possibility of establishing a space for critical reflection between the lineup, the intangible concept and narrative, and the collection plan, the tangible products, the concrete and real. We argue that the field of fashion design can be developed in this way, i.e., that we educate fashion designers who to a greater extent than now can be involved in strategic and sustainable decisions. We believe that other design disciplines can learn something from this because fashion is a clear and archetypal discipline although there are infinitely many directions. Similarly, other design disciplines presumably have a number of well-known tools, which can be challenged and potentially used to create the space for dialogues and conversations that promote critical reflection within their realms. Thus, the practice of critical reflection contributes to the students' ability to challenge the familiarity of the field and the situation as we know it and move towards a necessary sustainable change and a green transition.

\section{REFERENCES}

[1] Lipovetski G. Hypermodern Times. 2005 (Polity Press).

[2] Kawamura Y. Fashion-ology. An Introduction to Fashion Studies. 2005 (Berg).

[3] Fletcher K. and Tham M. Earth Logic Fashion Action Research Plan. 2019 (The JJ Charitable Trust).

[4] Lerdahl E. Slagkraft. Håndbok i idéutvikling. 2007 (Gyldendal Norsk Forlag AS).

[5] Sustainable Development Goals. Goal 12: Ensure sustainable consumption and production patterns. https://www.un.org/sustainabledevelopment/sustainable-consumption-production/ [Accessed on 2021, 18 May].

[6] Dewey J. Experience \& Education. The Kappa Delta Pi Lecture Series. 1938 (Simon \& Schuster).

[7] Schön D. The Reflective Practitioner - How Professionals Think in Action. 1983 (New York: Basic Books).

[8] Karell E. and Niinimäki K. A Mixed-Method Study of Design Practices and Designers' Role in Sustainable-Minded Clothing Companies. Sustainability. 2020, no 12.

[9] Andersen-Andersen. https://andersen-andersen.com [Accessed on 2021, 18 May].

[10] Week of Wonder. https://weekofwonder.store [Accessed on 2021, 18 May].

[11] Hasling K. and Bang A. How associative material characteristics create textile reflection in design education. Journal of Textile Design Research and Practice, 2016, Vol 3, pp. 27-46. 